quite different than those measured at low pressure. When the NO was pumped out after reaction, the surface was covered by a monolayer of NO which had several binding states, the most tightly bound having a heat of adsorption of $\sim 30 \mathrm{kcal}$ $\mathrm{mol}^{-1}$. Oxygen adsorption on the $\mathrm{Pt}$ ribbon was also found to have a heat of adsorption of $\sim 50 \mathrm{kcal} \mathrm{mol}^{-1}$ as expected.

TPD and AES were only carried out after cooling the ribbon to $300 \mathrm{~K}$ and pumping out gases to $<10^{-8}$ Torr, and the states observed in reaction should be so weakly bound that they desorb upon pumpout.

Another set of experiments was carried out with TPD under reaction conditions at pressures between $10^{-4}$ and $10^{-2}$ Torr. The ribbon temperature and reaction rate were allowed to reach steady state after which the surface was heated to desorb all species and the TPD spectra were recorded. All species desorption properties were in agreement with those obtained at $10^{-8}$ Torr. These experiments also yielded equilibrium coverages of NO vs temperature. Isobars between $10^{-4}$ and
$10^{-3}$ Torr yielded a heat of adsorption of NO of $\sim 30 \mathrm{kcal}$ $\mathrm{mol}^{-1}$ under reaction conditions, in agreement with $\mathrm{UHV}$ results.

These results appear to indicate that the tightly bound states of NO and atomic oxygen are not those observed in reaction. The reaction data is consistent with weakly bound species, essentially physically adsorbed, being reactive. However, TPD shows that the tightly bound state of NO is present during reaction. The explanation which appears to agree with all data is that reaction involves a weakly bound precursor intermediate species. We have shown that the kinetics should then exhibit the properties of the precursor state only. Apparently reaction of NO proceeds through a weakly bound state which is inhibited by a weakly bound state of oxygen. Recent results in this laboratory on the reaction between NO and CO confirm that weakly bound states may also be reactive.

a) This work partially supported by NSF under grant No. DMR75-02627.

b) Monsanto Corporation, St. Louis, MO.

\title{
Summary Abstract: Oxidation of carbon monoxide over Ag (111) by preadsorbed active oxygen studied by XPS and UPS ${ }^{\text {a) }}$
}

\author{
T. E. Felter and W. H. Weinberg ${ }^{\text {b) }}$ \\ Division of Chemistry and Chemical Engineering, California Institute of Technology, Pasadena, California 91125
}

P. A. Zhdan and G. K. Boreskov

Institute of Catalysis, The Academy of Sciences of the U.S.S.R., Novosibirsk, U.S.S.R. 630090

(Received 5 September 1980; accepted 31 December 1980)

PACS numbers: $81.60 . \mathrm{Hv}, 79.60 . \mathrm{Gs}, 82.65 . \mathrm{Nz}$

Recently, the oxidation of adsorbed carbon monoxide has attracted attention as a simple surface chemical reaction amenable to various surface-sensitive techniques. For example, $\mathrm{CO}$ oxidation over $\operatorname{Ir}(111),{ }^{1-3} \operatorname{Ir}(110),{ }^{4} \mathrm{Pt},{ }^{5,6} \mathrm{Rh}, 7,8$ $\mathrm{Ag}(110),{ }^{9} \mathrm{Pd},{ }^{10-12}$ and $\mathrm{Cu}(110)^{13}$ have been studied, usually by mass spectrometry, ${ }^{2-11}$ but also by XPS, ${ }^{1,3}$ molecular beams, ${ }^{12}$ LEED, ${ }^{10}$ and work function and ellipsometry measurements. ${ }^{13}$ In the present work, the kinetics of $\mathrm{CO}$ oxidation over Ag(111) was studied by monitoring XPS intensities. The electronic structure is revealed by XPS and UPS and is presented elsewhere in a more comprehensive paper. ${ }^{14}$

The VG ESCA-3 hemispherical electron spectrometer, with UV and x-ray (1486.6) sources, ${ }^{1}$ calibration, sample preparation, in situ cleaning by $\mathrm{Ar}^{+}$bombardment, annealing, and temperature control have all been described previously. 15
Oxygen adsorbs on $\mathrm{Ag}(111)$ at $300 \mathrm{~K}$ provided a hot (1500 K) $\mathrm{Pt}$ filament is nearby. The filament was a $9 \mathrm{~cm}$ length of $0.5 \mathrm{~mm}$ diameter very high purity wire that was tightly coiled and placed "line of sight," $3.5 \mathrm{~cm}$ from the front face of the $\mathrm{Ag}$ (111) sample. The adsorbed oxygen exhibits an asymmetrical $0 \mathrm{l} s$ line at $528.5 \mathrm{eV}$ with a full width at half maximum of approximately $1.6 \mathrm{eV}$ and valence levels at 1.8 and approximately $5 \mathrm{eV}$, and is denoted active oxygen because it reacts readily with incident $\mathrm{CO}$ molecules. Probably the hot Pt excites, e.g. triplet $\rightarrow$ singlet rather than dissociates the oxygen. Apparently, the excited (unlike the ground state) molecule adsorbs with a high sticking coefficient, $S$, on $\operatorname{Ag}(111)$, where it dissociatively adsorbs. With the filament off, $S \sim 0$. On Ag(110), Wachs and Madix ${ }^{16}$ observed a similar, but much less dramatic effect due either to pronounced 


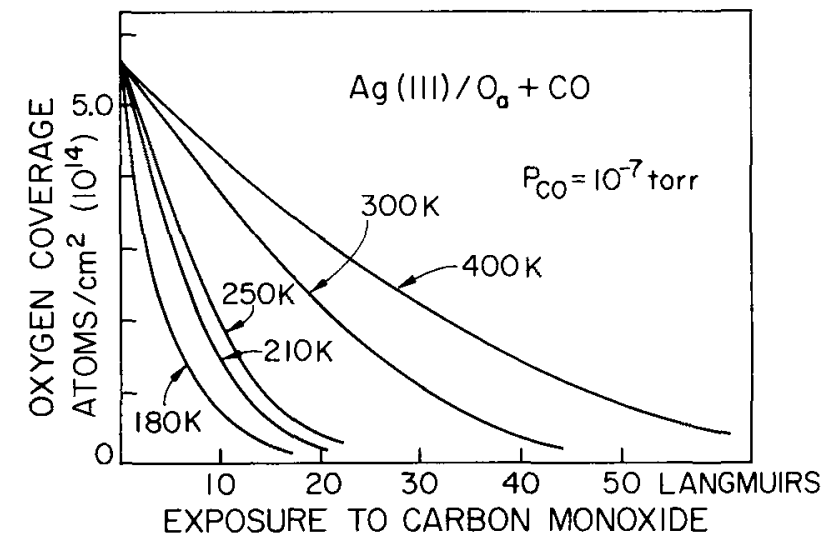

FIG. 1. Absolute XPS coverage determination for oxygen ${ }^{14,15,17}$ during reaction with $\mathrm{CO}$.

crystallographic specificity, or inadvertent excitation by other hot filaments or the VacIon pump. All filaments were off and oil diffusion pumps were employed in the present work.

Transient kinetics measured in the spectrometer during exposure of $\mathrm{Ag}(111) / \mathrm{O}$ to $\mathrm{CO}$ at an estimated ${ }^{1} 10^{-7}$ Torr $(1.33$ $\times 10^{-5} \mathrm{~Pa}$ ) are shown in Fig. 1 for various substrate temperatures, $T$, between 180 and $400 \mathrm{~K}$. The ordinate is the $0 \mathrm{ls}$ intensity for active oxygen at $528.5 \mathrm{eV}$, scaled according to the absolute coverage determination of Zhdan et al. ${ }^{14,15,17}$ Evidently, $[\mathrm{O}]$, the active oxygen coverage is depleted by impinging $\mathrm{CO}$, either by conversion to another adsorbed state with different $\mathrm{O} l s$ binding energy, or by removal by chemical reaction. Supplemental XPS experiments rule out the former and we assume the removal product to be $\mathrm{CO}_{2}(g)$. The removal rate increases with decreasing $T$, but it is always at least three times smaller than the incident rate of $\mathrm{CO}$ impingement.

Since supplemental experiments also showed no significant carbon $1 s$ intensity, clearly a second CO removal mechanism dominates over $\mathrm{CO}_{2}(\mathrm{~g})$ production by at least a factor of two. The simplest is, of course, first order CO desorption. Thus, the mass balance equation (assuming $S=1$ for $\mathrm{CO}$ ) is

$$
\frac{P_{\mathrm{CO}}}{\sqrt{2 \pi k T M}}=\frac{-d[\mathrm{O}]}{d t}+\nu_{\mathrm{CO}}[\mathrm{CO}] \exp \left(-E_{\mathrm{CO}} / k T\right) \text {. }
$$

For our coverage regime, the Langmuir-Hinshelwood mechanism is a reasonable starting point ${ }^{1-14,16}$ :

$$
\begin{aligned}
\frac{-d[\mathrm{O}]}{d t}=\nu_{\mathrm{CO}_{2}}^{\prime}[\mathrm{CO}][\mathrm{O}] \exp \left(-E_{\mathrm{CO}_{2}}^{\prime} / k T\right) & \\
& =\left\{\begin{array}{c}
\text { Rate of } \mathrm{CO}_{2}(g) \\
\text { formation }
\end{array}\right\},
\end{aligned}
$$

where the prime indicates rate constants for the rate limiting reaction step- $-\mathrm{CO}_{2}$ desorption being undoubtedly instantaneous at these temperatures. Substituting Eq. (2) into Eq (1) and rearranging, gives

$$
\frac{-d[\mathrm{O}]}{d t}=\left\{\frac{P_{\mathrm{CO}}}{\sqrt{2 \pi k T M}} \frac{\nu[\mathrm{O}] \exp (-E / k T)}{\nu[\mathrm{O}] \exp (-E / k T)+1}\right\},
$$

where $\nu \equiv \nu_{\mathrm{CO}_{2}}^{\prime} / \nu_{\mathrm{CO}}$ and $\mathrm{E} \equiv \mathrm{E}_{\mathrm{CO}_{2}}^{\prime}-\mathrm{E}_{\mathrm{CO}}$.
Since the incident rate of $\mathrm{CO}$ impingement is at least three times smaller than the rate of $\mathrm{CO}_{2}$ formation, the latter is less than half the rate of $\mathrm{CO}$ desorption. Therefore, their ratio (the first term in the denominator) is small compared to unity and Eq. (3) then becomes

$$
\Gamma \equiv-\ln \left(\frac{\sqrt{2 \pi k T M}}{P_{\mathrm{CO}}} \times \frac{-d[\mathrm{O}]}{d t}\right)=\frac{E}{k T}-\ln [\mathrm{O}] \nu,
$$

which is plotted in Fig. 2 for $t=0$, along with a straight line least squares fit wherein $E=-1.4 \mathrm{kcal} / \mathrm{mole}$ and $\nu=10^{-17}$ $\mathrm{cm}^{2}$. The linearity of Fig. 2 further corroborates that Eq. (4) is a suitable approximation to Eq. (3). A recent study by Bowker et al. for $\mathrm{CO}$ oxidation over $\mathrm{Ag}(110)^{9}$ gives these values to be $-1.1 \mathrm{kcal} / \mathrm{mole}$ and $1.5 \times 10^{-17} \mathrm{~cm}^{2} .{ }^{18}$ Note that $E$ is known to a greater accuracy $(\sim 0.1 \mathrm{kcal} / \mathrm{mole})$ than is possible for either of the difference terms defining it. The negative sign for $E$ indicates $\mathrm{CO}_{2}$ formation is energetically favored over CO desorption. Nevertheless, CO desorption is kinetically favored, i.e. more frequent because $\mathrm{CO}_{2}(g)$ production depends on $[\mathrm{CO}]$ which is small since $180 \mathrm{~K}$ exceeds the $\mathrm{CO}$ desorption temperature, $T_{d}$. In other words, since the $\mathrm{CO}$ is weakly chemisorbed, ${ }^{21}$ the residence time at the relatively warm temperatures employed here $(\geq 180 \mathrm{~K})$ is too small to allow for significant reaction with adsorbed oxygen.

For a sufficiently low temperature, however, the first term in the denominator of Eq. (3) dominates so that the rate of $\mathrm{CO}$ incidence flux is equal to that of $\mathrm{CO}_{2}(\mathrm{~g})$ production. In this regime $\Gamma=0$, a horizontal line through the origin in Fig. 2. The intersection with Eq. (4), at $137 \mathrm{~K}$, is a crude measure of $T_{d}$ and agrees with values obtained by TDMS for similar systems. ${ }^{9,19,20,21}$ In particular, for $\mathrm{W}(100) / \mathrm{Xe}, T_{d}=145 \mathrm{~K}$, and $\nu_{\mathrm{Xe}}=3 \times 10^{14} \mathrm{~s}^{-1}$ and $E_{\mathrm{Xe}}=9.3 \mathrm{kcal} / \mathrm{mole}^{19}$ If these values are appropriate to $\mathrm{CO} / \mathrm{Ag}(111)$, we estimate $\nu_{\mathrm{CO}_{2}}^{\prime}=$ $3 \times 10^{-3} \mathrm{~cm}^{2} / \mathrm{s}$ (typical for second order) and $E_{\mathrm{CO}_{2}}^{\prime}=7.9$ $\mathrm{kcal} / \mathrm{mole}$. Alternatively, by employing isosteric measurements of the adsorption of $\mathrm{CO}$ on $\mathrm{Ag}(111)$ (which do not yield the pre-exponential) ${ }^{21}$ where the heat of adsorption was found

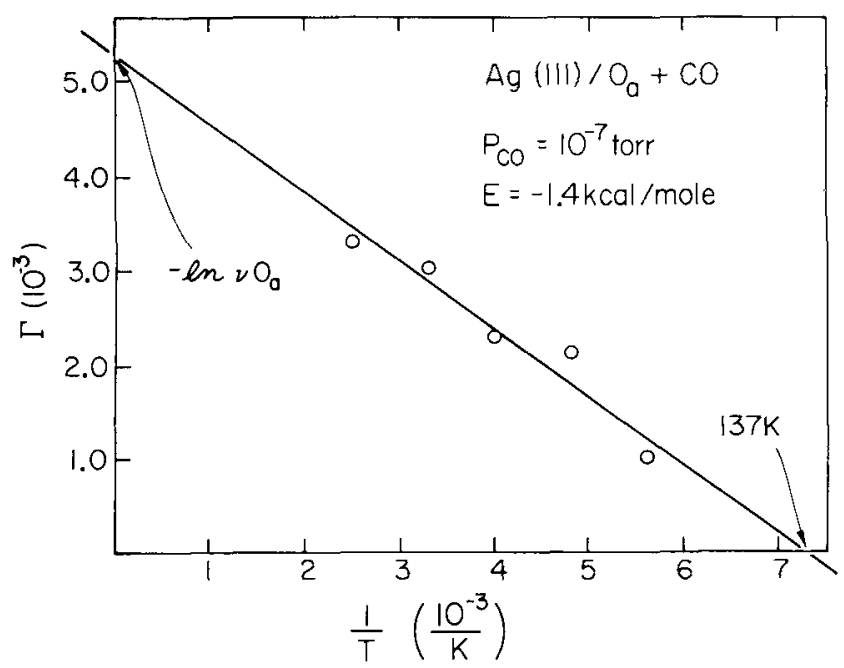

Fig. 2. Plot of Eq. (4) (see text) for the data of Fig. 1 at $t=0,|O|=5.6 \times$ $10^{14}$ atoms $/ \mathrm{cm}^{2}$. 
to be $6.5 \mathrm{kcal} / \mathrm{mole}$, we estimate $\mathrm{E}_{\mathrm{CO}_{2}}^{\prime}=5.1 \mathrm{kcal} / \mathrm{mole}$, in agreement with Bowker's study $5.2 \mathrm{kcal} / \mathrm{mole}^{9}$ employing the same $E_{\mathrm{CO}}$. Since the rate parameters $\nu$ and $E$ for $\mathrm{CO}$ oxidation over the $\mathrm{Ag}(111)$ surface (present study) are very similar indeed to those over $\operatorname{Ag}(110)^{9}$ we conclude that similar reaction mechanisms are involved.

a) Supported by the National Science Foundation under Grant No. CHE7710629A02

${ }^{b)}$ Camille and Henry Dreyfus Foundation Teacher-Scholar.

'P. A. Zhdan, G. K. Boreskov, W. F. Egelhoff, Jr., and W. H. Weinberg, Surf. Sci. 61, 377 (1976).

${ }^{2}$ V. P. Ivanov, G. K. Boreskov, V. I. Savchenko, W. F. Egelhoff, Jr., and W. H. Weinberg, J. Catal. 48, 269 (1977)

${ }^{3}$ P. A. Zhdan, G. K. Boreskov, A. I. Boronin, A. P. Schepelin, S. P. Withrow, and W. H. Weinberg, Appl. Surf. Sci. 3, 145 (1979).

${ }^{4}$ J. L. Taylor, D. E. Ibbotson, and W. H. Weinberg, Surf. Sci. 90, 37 (1979); J. Catal. 61, 1 (1980).

${ }^{5}$ G. K. Hori and L. D. Schmidt, J. Catal. 38, 335 (1975).

${ }^{6}$ H. P. Bonzel and J. J. Burton, Surf. Sci. 52, 223 (1975).
${ }^{7}$ C. T. Campbell, S.-K. Shi, and J. M. White, J. Phys. Chem. 83, 2255 (1979).

${ }^{8}$ H.-I. Lee, G. Praline, and J. M. White, Surf. Sci. 91, 581 (1980).

${ }^{9}$ M. Bowker, M. A. Barteau, and R. J. Madix, Surf. Sci. 92, 528 (1980).

${ }^{10} \mathrm{G}$. Ertl and J. Koch, 5th Proc. Int. Congr. Catal., 969 (1973).

${ }^{11}$ T. Matsushima, C. J. Mussett, and J. M. White, J. Catal. 41, 397 (1976).

${ }^{12}$ T. Engel and G. Ertl, J. Chem. Phys. 69, 1267 (1978).

${ }^{13}$ F. H. P. M. Habraken, G. A. Bootsma, P. Hofmann, S. Hachiche, and A. M. Bradshaw, Surf. Sci. 88, 285 (1979).

${ }^{14}$ T. E. Felter, W. H. Weinberg, G. Ya. Lastushkina, and P. A. Zhdan, (to be published).

${ }^{15}$ T. E. Felter, W. H. Weinberg, P. A. Zhdan, and G. K. Boreskov, Surf. Sci. Lett. 97, L313 (1980).

${ }^{16}$ I. E. Wachs and R. J. Madix, Surf. Sci. 76, 531 (1978).

${ }^{17}$ P. A. Zhdan, (to be published).

${ }^{18}$ The frequency factor ratio is obtained from their intercept of $0.002 \mathrm{sec}-$ onds $^{-1}$ upon division by $F=3 \times 10^{14}$ molecules $/ \mathrm{cm}^{2} \mathrm{~s}$, (their calibration for the gas flux from their doser) and multiplication by $\ln 10$.

${ }^{19} \mathrm{G}$. Doyan and G. Ertl, Surf. Sci. 69, 157 (1977), and references therein.

${ }^{20}$ C.-M. Chan, R. Aris, and W. H. Weinberg, Appl. Surf. Sci. 1, 360 (1978).

${ }^{21}$ G. McElhiney, H. Papp, and J. Pritchard, Surf. Sci. 54, 617 (1976). 